\title{
Erratum to: The proximate cause of asynchronous hatching in the burying beetle Nicrophorus quadripunctatus
}

\author{
Mamoru Takata $^{1} \cdot$ Shinya Hayashi $^{2} \cdot$ Cathleen E. Thomas $^{3} \cdot$ Satoshi Koyama $^{2}$
}

Published online: 3 March 2016

(C) Japan Ethological Society and Springer Japan 2016

Erratum to: J Ethol (2015) 33:197-203

DOI 10.1007/s10164-015-0431-y

Unfortunately, the axis labels for Figs. 4 and 5 were published with errors. It should be "Egg volume $\left(\mathrm{mm}^{3}\right)$ " instead of "Egg volume $\left(\mathrm{cm}^{3}\right)$ ".

The online version of the original article can be found under doi:10.1007/s10164-015-0431-y.

Satoshi Koyama

skoyama@cc.tuat.ac.jp; drone.honeybee@gmail.com

Mamoru Takata

mamorururu2000@yahoo.co.jp; fugoh@cc.tuat.ac.jp

Cathleen E. Thomas

cathleen.thomas@ncl.ac.uk

1 United Graduate School of Agricultural Science, Tokyo

University of Agriculture and Technology, 3-5-8 Saiwai,

Fuchu, Tokyo, Japan

2 Graduate School of Agriculture, Tokyo University of Agriculture and Technology, 3-5-8 Saiwai, Fuchu, Tokyo, Japan

3 School of Biology, Newcastle University, Newcastle upon Tyne NE1 7RU, UK 